\title{
Neurobiological Dissociation of Retrieval and Reconsolidation of Cocaine-Associated Memory
}

\author{
James M. Otis, Kidane B. Dashew, and Devin Mueller \\ Department of Psychology, University of Wisconsin-Milwaukee, Milwaukee, Wisconsin 53201-0413
}

\begin{abstract}
Drug use is provoked by the presentation of drug-associated cues, even following long periods of abstinence. Disruption of these learned associations would therefore limit relapse susceptibility. Drug-associated memories are susceptible to long-term disruption during retrieval and shortly after, during memory reconsolidation. Recent evidence reveals that retrieval and reconsolidation are dependent on $\beta$-adrenergic receptor $(\beta$-AR) activation. Despite this, whether retrieval and reconsolidation are dependent on identical or distinct neural mechanisms is unknown. The prelimbic medial prefrontal cortex (PL-mPFC) and basolateral amygdala (BLA) have been implicated in the expression and reconsolidation of associative memories. Therefore, we investigated the necessity of $\beta$-AR activation within the PL-mPFC and BLA for cocaine-associated memory retrieval and reconsolidation in rats. Before or immediately after a cocaineinduced conditioned place preference (CPP) retrieval trial, $\beta$-AR antagonists were infused into the PL-mPFC or BLA, followed by daily testing. PL-mPFC infusions before, but not after, a CPP trial disrupted CPP memory retrieval and induced a persistent deficit in retrieval during subsequent trials. In contrast, BLA $\beta$-AR blockade had no effect on initial CPP memory retrieval, but prevented CPP expression during subsequent trials indicative of reconsolidation disruption. Our results reveal a distinct dissociation between the neural mechanisms required for cocaine-associated memory retrieval and reconsolidation. Using patch-clamp electrophysiology, we also show that application of a $\beta$-AR antagonist prevents norepinephrine-induced potentiation of PL-mPFC pyramidal cell and $\gamma$-aminobutyric-acid (GABA) interneuron excitability. Thus, targeted $\beta$-AR blockade could induce long-term deficits in drug-associated memory retrieval by reducing neuronal excitability, providing a novel method of preventing cue-elicited drug seeking and relapse.
\end{abstract}

\section{Introduction}

Drug-associated cues evoke craving and relapse in addicts (Childress et al., 1986; Heather et al., 1991), and disrupting these associations would limit relapse susceptibility. Drug-associated memories are susceptible to persistent disruption during retrieval and shortly after, during memory reconsolidation. Reconsolidation is the process by which a retrieved memory enters a labile state and is subsequently restabilized (Nader et al., 2000). Recent evidence demonstrates that $\beta$-adrenergic receptor ( $\beta$-AR) signaling is required for both drug-associated memory retrieval and reconsolidation, as disruption of this signaling during retrieval or reconsolidation impairs cue-induced drug seeking and prevents reinstatement (Fricks-Gleason and Marshall, 2008; Milton et al., 2008a; Otis and Mueller, 2011). Despite this requirement of $\beta$-ARs in retrieval and reconsolidation of drug-associated memories, whether these processes depend on similar or distinct neurobiology is unknown.

Received July 19, 2012; revised Nov. 16, 2012; accepted Dec. 4, 2012.

Author contributions: J.M.O. and D.M. designed research; J.M.O. and K.B.D. performed research; J.M.O. and D.M. analyzed data; J.M.O. and D.M. wrote the paper.

This research was supported by DA027870 and a grant from the University of Wisconsin-Milwaukee Research Growth Initiative (D.M.). We thank Dr. James Moyer, Dr. Marieke Gilmartin, Chenghui Song, Megha Sehgal, Patrick Reilly, Michael Fitzgerald, Julia Wong, and Janine Kwapis for technical assistance, as well as Dr. Fred Helmstetter for comments regarding early versions of this manuscript.

Correspondence should be addressed to Dr. Devin Mueller, Department of Psychology, University of WisconsinMilwaukee, P.0. Box 413, Milwaukee, WI 53201-0413.E-mail: devinm@uwm.edu.

DOI:10.1523/JNEUROSCI.3463-12.2013

Copyright $\odot 2013$ the authors $\quad 0270-6474 / 13 / 331271-11 \$ 15.00 / 0$
The prelimbic medial prefrontal cortex (PL-mPFC) and basolateral amygdala (BLA) have been implicated in the behavioral expression of memories. As behavioral expression of memory is dependent on memory retrieval, the PL-mPFC and BLA are promising candidates for drug-associated memory retrieval. The PL-mPFC and BLA are engaged by exposure to drug-associated cues in both rodents (Miller and Marshall, 2004, 2005) and human addicts (Childress et al., 2008; Goudriaan et al., 2010), and the intensity of prefrontal and amygdala activation positively correlates with reported drug cravings (Grant et al., 1996; Kilts et al., 2001). Activation of the PL-mPFC is necessary for expression of associative memories (Corcoran and Quirk, 2007), including cue-induced drug seeking (Hiranita et al., 2006; Han et al., 2010). BLA inactivation prevents expression of conditioned place preference (CPP) and cue-induced reinstatement of cocaine selfadministration (Brown and Fibiger, 1993; Grimm and See, 2000), and BLA $\beta$-AR blockade prevents CPP memory reconsolidation (Bernardi et al., 2009). Whether these structures mediate retrieval and reconsolidation of drug-associated memories, and whether they do so distinctly or in concert, however, remain unknown. Neurons within these regions receive noradrenergic input from the locus ceruleus (Loughlin et al., 1982). Thus, $\beta$-AR activation within PL-mPFC and BLA may be critical for drug-associated memory retrieval and reconsolidation.

We determined the necessity of PL-mPFC and BLA $\beta$-ARs for retrieval and reconsolidation of a cocaine-associated CPP memory by infusing $\beta$-AR antagonists before or after a retrieval trial. Previously, we showed that systemic $\beta$-AR blockade persistently 
disrupts CPP memory retrieval, allowing for differentiation between behavioral expression within a trial and memory retrieval across trials (Otis and Mueller, 2011). Therefore, following the infusion trial rats were given infusion-free CPP retrieval trials to differentiate between persistent effects of the infusion on memory retrieval or reconsolidation and acute effects of the infusion on behavioral expression of the CPP. Additionally, we used whole-cell patch-clamp recordings to investigate the physiological consequences of $\beta$-AR blockade on intrinsic excitability of PL-mPFC pyramidal cells and $\gamma$-aminobutyric-acid (GABA) interneurons following norepinephrine (NE) application. Our results reveal a structural dissociation between retrieval and reconsolidation, and demonstrate that disruption of either memory process with $\beta$-AR antagonists provokes long-lasting impairments in drug seeking.

\section{Materials and Methods}

Subjects and surgery. Male Long-Evans rats aged 3-5 months weighing $300-325 \mathrm{~g}$ were individually housed in clear plastic cages. Rats were maintained on a 14/10 h light/dark cycle (lights on at 0700), during which they had both water and standard laboratory rat chow ad libitum (Harlan Laboratories). Rats were weighed and handled daily for $3 \mathrm{~d}$ before surgery. All experimental protocols were approved by the Institutional Animal Care and Use Committee at the University of Wisconsin-Milwaukee in accordance with National Institutes of Health guidelines.

Rats were anesthetized with ketamine/xylazine $(90 \mathrm{mg} / \mathrm{kg}, 10.5 \mathrm{mg} / \mathrm{kg}$, i.p.), and implanted with a 26 gauge double-barrel guide cannula (Plastics One) aimed at the PL-mPFC (anteroposterior, AP: +2.8; mediolateral; ML: \pm 0.6 ; dorsoventral, DV: $-2.9 \mathrm{~mm}$ relative to bregma) or two single-barrel guide cannulae aimed at the BLA (AP, -2.8 ; ML, \pm 5.0 ; DV, $-8.1 \mathrm{~mm}$ relative to bregma). Guide cannulae were fixed to the skull with three stainless steel skull screws and grip cement. Stylets were inserted into the guide cannulae to maintain patency until infusions were made. Following surgery, rats were injected with an antibiotic (75,000 U in 0.25 $\mathrm{ml}$, s.c.) and an analgesic (carprofen, $5.0 \mathrm{mg}$ in $0.1 \mathrm{ml}$, s.c.). Rats were then allowed a minimum of $7 \mathrm{~d}$ to recover before behavioral testing.

Drugs. Cocaine $\mathrm{HCl}$ (National Institute on Drug Abuse) was dissolved in sterile $0.9 \%$ saline at a concentration of $10 \mathrm{mg} / \mathrm{ml}$, and administered at a dose of $10 \mathrm{mg} / \mathrm{kg}$ (i.p.). The $\beta$-AR antagonists propranolol and nadolol (Sigma-Aldrich) were dissolved in sterile $0.9 \%$ saline at a concentration of $10 \mu \mathrm{g} / \mu \mathrm{l}$ and $2 \mu \mathrm{g} / \mu \mathrm{l}$, respectively. Microinfusions of propranolol, nadolol, or saline into the PL-mPFC or BLA occurred at a rate of 0.3 $\mu \mathrm{l} / \mathrm{side} / 1.5 \mathrm{~min}$. These doses and rates of microinfusions were based on previous investigations using propranolol and nadolol (Murchison et al., 2004; Mueller et al., 2008).

Place preference apparatus. Behavioral testing and conditioning were conducted as previously described (Mueller and Stewart, 2000; Otis and Mueller, 2011). Briefly, a three-chamber apparatus was used in which two larger conditioning chambers were separated by a smaller center chamber. Rats were isolated in the larger chambers during conditioning, which had distinct walls and flooring. During baseline and postconditioning CPP trials, rats had access to the entire apparatus. Time was recorded during CPP trials with four infrared photobeams located in the larger chambers. In addition, total numbers of photobeam breaks were recorded during CPP trials to quantify locomotor activity. During all phases of the experiments the room was kept in semidarkness.

Behavioral testing and microinfusions. Baseline preferences were determined by placing the rats into the center chamber with free access to the entire apparatus for $15 \mathrm{~min}$. Time spent in each chamber was recorded. As expected, rats spent an equivalent amount of time in the conditioning chambers during the baseline trial, but less time in the center chamber. ANOVA revealed a significant effect of chamber for all rats during the baseline preference trial $\left(F_{(2,230)}=234.18, p<0.001\right)$, and post hoc analyses confirmed that an equivalent amount of time was spent within the conditioning chambers $(p=1.00)$, but less time was spent within the center chamber than in either of the conditioning chambers $(p s<$ $0.001)$. Therefore, an unbiased procedure was used, in which rats were assigned to receive cocaine in one of the two larger chambers indepen- dent of baseline preference scores in a pseudorandom fashion. Following baseline testing, rats were conditioned to associate one chamber, but not another, with cocaine in a counterbalanced fashion over $8 \mathrm{~d}$. Injections of saline or cocaine were given immediately before each 20 min conditioning session, during which the rats were confined to their respective chambers. Following conditioning, all rats were adapted to microinfusion procedures. Microinfusion injector tips extended $0.5 \mathrm{~mm}$ past the guides for BLA microinfusions, and $1.0 \mathrm{~mm}$ past the guides for PL-mPFC microinfusions. To allow for microinfusion adaptation, the first day following conditioning injectors were lowered to the microinfusion site for 2 min but no drug was infused. The following day saline was infused at the same rate and volume as infused during subsequent drug manipulation. These procedures allowed for the rats to adapt to changes in cranial pressure and mechanical stimulation induced during microinfusions.

Following conditioning and microinfusion adaptation, rats were given daily CPP trials during which they were placed into the center chamber and allowed free access to the entire apparatus for $15 \mathrm{~min}$. A CPP was determined when significantly more time was spent in the previously cocaine-paired chamber than in the saline-paired chamber. To identify the necessity of $\beta$-AR activation within the PL-mPFC and BLA for CPP memory retrieval, propranolol or saline were infused $15 \mathrm{~min}$ before the second CPP trial, after a CPP had previously been expressed. Moreover, to ensure that the effects of propranolol were specific to $\beta$-AR blockade and not due to nonspecific effects, separate groups of rats were infused with the specific $\beta$-AR antagonist nadolol (Goodman et al., 2001). Nadolol was infused 15 min before an initial CPP test, as opposed to the second test, as previous evidence suggests that $\beta$-AR blockade is capable of preventing retrieval during an initial CPP trial (Otis and Mueller, 2011). Finally, to determine the necessity of PL-mPFC and BLA $\beta$-AR activation in drug-associated memory reconsolidation, separate rats were infused with nadolol immediately after an initial CPP trial. Following the microinfusion $\mathrm{CPP}$ trial, rats continued daily drug-free trials to determine whether nadolol or propranolol infusions caused persistent disruptions in CPP memory retrieval or reconsolidation. To control for possible effects of microinfusions that were independent of memory retrieval or reconsolidation, separate groups of rats were also infused with nadolol or saline in the absence of a CPP trial followed by a CPP trial the next day.

The possible aversive or appetitive effects of nadolol microinfusions were also examined. Following baseline testing, rats were conditioned to associate one chamber, but not another, with nadolol in a counterbalanced fashion over $2 \mathrm{~d}$. PL-mPFC or BLA microinfusions of nadolol or saline were administered $15 \mathrm{~min}$ before normal conditioning sessions, in which the rats were confined to their respective chambers. Following conditioning, rats were given a normal drug-free CPP trial.

Histology. Following behavioral testing, rats were killed with an overdose of pentobarbital and transcardially perfused with $0.9 \%$ saline followed by $10 \%$ buffered formalin. Brains were then removed and stored in a $30 \%$ sucrose/formalin solution. Following brain submersion, $50 \mu \mathrm{m}$ coronal sections were stained with cresyl violet to confirm the injector tip locations. One rat was excluded from analysis due to injector tip misplacement.

Behavioral data analysis. Drug-seeking behavior during CPP trials was analyzed by comparing time spent in the previously cocaine-paired, saline-paired, and center chambers across trials and between groups using a repeated-measures ANOVA. Following a significant chamber by group interaction or chamber by group by day interaction, Tukey's HSD post hoc tests were used to compare the amount of time spent in the previously cocaine-paired versus saline-paired chambers for single or across multiple CPP trials for each group. Locomotor activity was quantified as the number of photobeam breaks during the CPP infusion trial, and analyzed using an independent-samples $t$ test.

Patch-clamp electrophysiology. Rats aged 3-5 months were anesthetized with pentobarbital, and their brains were rapidly removed and transferred to ice-cold, oxygenated $\left(95 \% \mathrm{O}_{2} / 5 \% \mathrm{CO}_{2}\right)$ artificial CSF (aCSF) containing the following composition (in $\mathrm{mM}$ ): $124 \mathrm{NaCl}, 2.8$ $\mathrm{KCl}, 1.25 \mathrm{NaH}_{2} \mathrm{PO}_{4}, 2 \mathrm{MgSO}_{4}, 2 \mathrm{CaCl}_{2}, 26 \mathrm{NaHCO}_{3}$, and 20 dextrose. Coronal slices $400 \mu \mathrm{m}$ thick were cut using a vibrating blade microtome (Leica VT1200) and allowed to recover in warm aCSF $\left(32-35^{\circ} \mathrm{C}\right)$ for 30 
Table 1. Basic membrane properties of PL-mPFC pyramidal and GABAergic neurons

\begin{tabular}{|c|c|c|c|c|c|c|}
\hline Neuron & $\mathrm{R}_{\mathrm{N}}(\mathrm{M} \Omega)$ & $V_{\mathrm{m}}(\mathrm{mV})$ & $\mathrm{AP}_{\text {width }}$ (ms) & $\mathrm{AP}_{\mathrm{amp}}(\mathrm{mV})$ & fAHP (mV) & sAHP (mV) \\
\hline Pyramidal & $125 \pm 11$ & $-69 \pm 2$ & $2.6 \pm 0.2$ & $67 \pm 2$ & $-6.4 \pm 0.6$ & $-0.7 \pm 0.1$ \\
\hline GABA & $310 \pm 6^{* * *}$ & $-66 \pm 1$ & $2.1 \pm 0.1^{* *}$ & $61 \pm 2^{*}$ & $-13.6 \pm 0.8^{* * *}$ & $-0.0 \pm 0.1^{* * *}$ \\
\hline
\end{tabular}

$\mathrm{AP}_{\text {width }}$, action potential width; $\mathrm{AP}$ amp , action potential amplitude; $\mathrm{R}_{\mathrm{N}}$, input resistance; $V_{\mathrm{m}}$, resting membrane potential; $f \mathrm{AHP}$, fast afterhyperpolarization; sAHP, slow afterhyperpolarization. ${ }^{*} p<0.05$, ${ }^{* *} p<0.01,{ }^{* * *} p<0.001$ as compared with pyramidal neurons.

min, followed by incubation in room-temperature aCSF until use in experiments. Slices were transferred to a submersion recording chamber, mounted, and perfused with warm aCSF $\left(\sim 2 \mathrm{ml} / \mathrm{min} ; 32^{\circ} \mathrm{C}\right)$. Pyramidal neurons with visible apical dendrites or smaller GABAergic neurons in layers II/III or V of PL-mPFC were visualized with differential interference contrast using a $60 \times$ water-immersion lens on an upright Eclipse FN1 microscope (Nikon Instruments). Whole-cell patch-clamp recordings of PL-mPFC pyramidal neurons and GABAergic interneurons were obtained using fire-polished borosilicate glass pipettes (3-8 $\mathrm{M} \Omega$ ), filled with internal solution containing the following composition (in $\mathrm{mM}$ ): $110 \mathrm{~K}$-gluconate, $20 \mathrm{KCl}, 10 \mathrm{HEPES}, 2 \mathrm{MgCl}_{2}$, 2 ATP, $0.3 \mathrm{GTP}, 10$ phosphocreatine; $0.2 \%$ biocytin, $\mathrm{pH} 7.3$, and $280 \mathrm{mOsm}$. Recordings were made with a patch-clamp amplifier (MultiClamp 700B; Molecular Devices) in current-clamp mode, filtered, digitized $(10 \mathrm{kHz})$, and saved using PClamp 10 (Molecular Devices).

Following $5 \mathrm{~min}$ of stable recording, neurons were polarized to approximately $-65 \mathrm{mV}$ to control for resting membrane potential variance. To measure input resistance $\left(\mathrm{R}_{\mathrm{N}}\right)$, a series of $1 \mathrm{~s}$ current steps $(-140$ to $+40 \mathrm{pA})$ were applied, and the resulting voltage deflections were used to create an IV plot. Rheobase was analyzed in a subset of pyramidal neurons and in all GABAergic neurons by applying $1 \mathrm{~s} \mathrm{current}$ steps with $10 \mathrm{pA}$ increments until a single action potential (AP) was elicited. To measure intrinsic excitability, a $2 \mathrm{~s}$ depolarizing step was administered every $7.5 \mathrm{~s}$ and evoked APs were recorded. The level of depolarizing step was adjusted to rheobase and remained constant throughout the experiment. Baseline current steps continued for at least $10 \mathrm{~min}$ before bath application of propranolol $(100 \mu \mathrm{M})$ and/or NE (100 $\mu \mathrm{M})$. Following recording, brain slices were fixed in phosphate buffered formalin overnight.

Immunohistochemistry. To reveal biocytin-filled pyramidal and GABAergic neurons, brain slices were washed in filtered $0.1 \mathrm{M}$ PBS, followed by $1 \% \mathrm{NaBH}_{4}$ in PBS and $10 \%$ normal goat serum (NGS). The slices were then incubated overnight with a mouse primary antibody for $\operatorname{GAD}_{67}$ (1:1000; Millipore), which is selectively expressed in GABAergic neurons, mixed with $3 \%$ NGS, $0.2 \%$ Triton-X, and PBS. The following day, slices were washed in PBS and incubated for $2 \mathrm{~h}$ in a red fluorescent secondary antibody for $\operatorname{GAD}_{67}$ (1:200; Alexa Fluor goat anti-mouse IgG) and a green fluorescent antibody for biocytin (streptavidin, 1:250; Invitrogen). Following a final wash of PBS, slices were mounted with antifade mounting medium and coverslipped. Slices were then visualized using $20 \times$ magnification with green and red florescent light, providing evidence that neurons were pyramidal neurons (green label only) or GABAergic neurons (double labeled). Immunolabeling, along with morphological and electrophysiological characteristics of the neurons, confirmed that patch-clamp recordings were from either PLmPFC pyramidal neurons (control, $n=4$; NE, $n=7$; $\mathrm{NE}+$ propranolol, $n=8$ ) or GABAergic interneurons (control, $n=13$; NE, $n=10 ; \mathrm{NE}+$ propranolol, $n=11)$.

Electrophysiology data analysis. Electrophysiological data were analyzed using Clampfit (Molecular Devices). To distinguish between PLmPFC pyramidal and GABAergic neurons, basic membrane properties were recorded, including input resistance $\left(\mathrm{R}_{\mathrm{N}}\right)$ and resting membrane potential $\left(V_{\mathrm{m}}\right)$. AP properties and fast afterhyperpolarization (fAHP) were analyzed using the first AP evoked from the current trace which elicited the most APs (Santini et al., 2008). To analyze fAHP, the voltage antipeak within 2-5 ms of the AP was compared with AP threshold (Storm, 1987; Karayannis et al., 2007). To analyze slow afterhyperpolarization (sAHP), voltage was recorded $1 \mathrm{~s}$ following current offset and was subtracted from baseline voltage before current injection (Kaczorowski et al., 2012). These properties were then compared using independent samples $t$ tests between pyramidal and GABAergic neurons.
Comparisons of basic membrane properties provided further evidence that neurons were either pyramidal or GABAergic (see Table 1). When compared with pyramidal neurons, GABAergic neurons had reduced AP width and AP amplitude, characteristic of other cortical GABAergic interneurons (McCormick et al., 1985; Karayannis et al., 2007). Importantly, these neurons also had greater fAHP amplitude, but lacked sAHP (McCormick et al., 1985; Karayannis et al., 2007), which prevented spike frequency adaptation (see Fig. 7B). Finally, GABAergic neurons had greater $\mathrm{R}_{\mathrm{N}}$, which may reflect their small size (McCormick et al., 1985).

Basic measures of intrinsic excitability were also analyzed before and immediately following drug application. Finally, to analyze AP frequency, the average number of spikes for every four current pulses was plotted against time.

\section{Results}

\section{PL-mPFC $\beta$-AR blockade induces a persistent deficit in retrieval of a CPP memory}

We first investigated the necessity of PL-mPFC $\beta$-AR activation for cocaine-associated CPP memory retrieval. Bilateral PL-mPFC microinfusions of saline $(n=10)$ or propranolol $(n=8)$ were administered $15 \mathrm{~min}$ before the second CPP trial (Fig. 1A; PL$\mathrm{mPFC}$ infusion sites). Following conditioning, all rats expressed a CPP for the previously cocaine-paired chamber during the first trial. Microinfusions of propranolol, but not saline, before the second trial prevented expression of the CPP during that trial and during a subsequent propranolol-free trial (Fig. 1B). ANOVA revealed a significant chamber by group by trial interaction $\left(F_{(4,64)}=3.05, p<0.05\right)$, but no significant group by chamber effect $\left(F_{(2,32)}=1.66, p>0.05\right)$. Moreover, Tukey's post hoc analyses confirmed that both groups spent more time in the previously cocaine-paired chamber than in the saline-paired chamber during the first CPP trial ( $p s<0.01$ ), indicating that both groups expressed a CPP. Following microinfusions of propranolol or saline before the second trial, however, only saline-treated rats spent significantly more time in the cocaine-paired chamber (post hoc $p<0.01$ ), while propranolol-treated rats spent an equivalent amount of time in all chambers (post hoc ps $>0.05$ ). This persisted during a subsequent infusion-free trial (i.e., trial 3 ) in which saline-treated rats spent significantly more time in the cocaine-paired chamber than in the saline-paired chamber (post hoc $p<0.05$ ), while propranolol-treated rats spent an equivalent amount of time in the cocaine- and saline-paired chambers (post hoc $p>0.05)$. The effects of propranolol were not due to nonspecific motor impairments as rats infused with saline $(n=10)$ or propranolol $(n=8)$ before a second CPP trial had comparable levels of photobeam breaks during that trial $\left(t_{(16)}=0.06, p>\right.$ 0.05 ; Fig. $1 D$ ). Thus, a single PL-mPFC microinfusion of propranolol induced a deficit in CPP memory retrieval, which persisted even during a subsequent drug-free trial.

At high doses, propranolol can act as a selective serotonergic receptor antagonist (Alexander and Wood, 1987) and can inhibit protein kinase $\mathrm{C}$ (Sozzani et al., 1992), in addition to $\beta$-AR blockade. Although our dose was not expected to have these effects, we nonetheless tested the more selective $\beta$-AR antagonist nadolol (Goodman et al., 2001) to ensure the observed retrieval deficits were due to $\beta$-AR blockade. Rats were pretested, conditioned, 
A

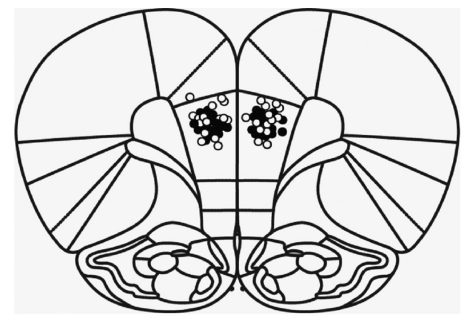

B

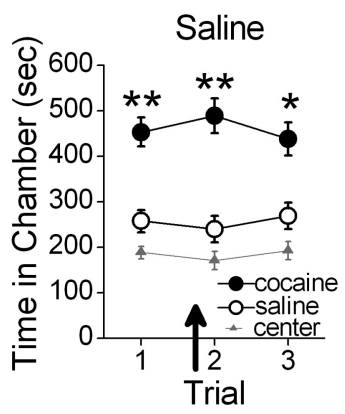

C

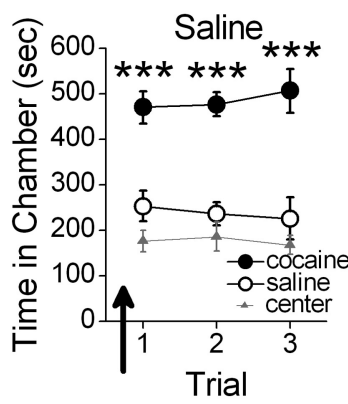

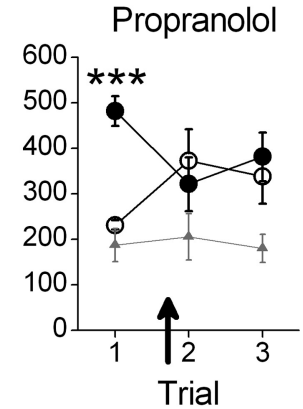

D

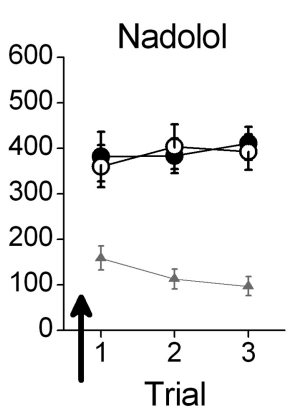

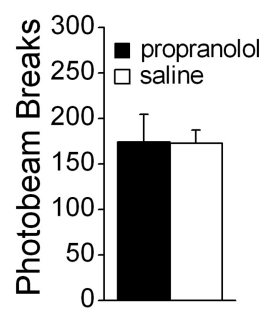

E

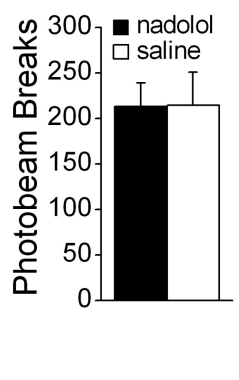

Figure 1. $\quad \beta$-AR blockade in PL-mPFC disrupts CPP memory retrieval. $A$, Coronal drawings (bregma, $+3.72 \mathrm{~mm}$ ) showing injector tip placements for PL-mPFC infusions. PL-mPFC infusions (arrows) of $(\boldsymbol{B})$ propranolol before a second CPP trial or $(\boldsymbol{C})$ nadolol before a first CPP trial, but not saline, prevented rats from expressing a $(P P$ during that trial and subsequent infusion-free trials. PL-mPFC infusions of $(\boldsymbol{D})$ propranolol or $(\boldsymbol{E})$ nadolol had no effect on locomotor activity, as measured by photobeam breaks, when administered before a $\left(P P\right.$ trial. ${ }^{* * *} p<0.001,{ }^{* *} p<0.01$, and ${ }^{*} p<0.05$. Error bars indicate SEM.

and subjected to daily CPP trials. Bilateral PL-mPFC microinfusions of saline $(n=7)$ or nadolol $(n=6)$ were administered 15 min before the first CPP trial, as previous evidence indicates that retrieval can be prevented by administering $\beta$-AR antagonists systemically before an initial CPP trial (Otis and Mueller, 2011). Rats infused with saline expressed a CPP for the previously cocaine-paired chamber during this trial and subsequent microinfusion-free trials, while rats infused with nadolol did not (Fig. 1C). ANOVA revealed a significant chamber by group interaction $\left(F_{(2,22)}=7.50, p<0.01\right)$, but no group by chamber by trial effect $\left(F_{(4,44)}=0.44, p>0.05\right)$. Post hoc analyses confirmed that during the first CPP trial, following microinfusions, salinetreated rats spent significantly more time in the cocaine-paired chamber than in the saline-paired chamber $(p<0.001)$, while nadolol-treated rats spent an equivalent amount of time in the cocaine- and saline-paired chambers $(p>0.05)$. Thus, only saline-infused rats expressed a CPP during the first trial. During all subsequent nadolol-free trials (i.e., trials 2-3), saline-treated rats continued to express a CPP while nadolol-treated rats did not. Post hoc analyses confirmed that saline-treated rats spent significantly more time in the cocaine-paired chamber than in the saline-paired chamber during these trials overall $(p<0.001)$, while nadolol-treated rats spent an equivalent amount of time in the cocaine- and saline-paired chambers $(p>0.05)$. Moreover, the effects of nadolol were not due to nonspecific motor impairments as rats infused with saline $(n=7)$ or nadolol $(n=8)$ before an initial CPP trial had comparable levels of photobeam breaks during that trial $\left(t_{(13)}=0.02, p>0.05\right.$; Fig. $\left.1 E\right)$. Together, PLmPFC microinfusions of $\beta$-AR antagonists induce a persistent deficit in CPP memory retrieval when administered before an initial trial or before a second trial after a CPP has previously been expressed.

\section{BLA $\beta$-AR blockade has no effect on retrieval, but prevents CPP memory reconsolidation}

BLA activity is necessary for expression of associative memories, including cue-induced drug seeking (Brown and Fibiger, 1993; Grimm and See, 2000; Fuchs et al., 2005). Thus, we determined the necessity of $\beta$-AR activation within the BLA for cocaineassociated CPP memory retrieval. Following conditioning, rats were subjected to daily CPP trials, with bilateral BLA microinfusions of saline $(n=13)$ or propranolol $(n=9)$ before the second trial (Fig. 2A; BLA infusion sites). All rats expressed a CPP for the previously cocaine-paired chamber during the first and second trial. During a subsequent infusion-free trial, however, salinetreated rats continued to express a CPP for the previously cocaine-paired chamber while propranolol-treated rats did not (Fig. 2B). ANOVA revealed no significant group differences (group by chamber, $F_{(2,40)}=0.79, p>0.05$; group by chamber by trial, $\left.F_{(4,80)}=0.59, p>0.05\right)$. However, there was a significant effect of chamber overall $\left(F_{(2,40)}=89.60, p<0.001\right)$. Post hoc analysis confirmed that all rats spent significantly more time in the previously cocaine-paired chamber than in the salinepaired chamber during the first CPP trial $(p<0.05)$. During the second trial, following microinfusions, both groups continued to spend more time in the previously cocaine-paired chamber than in the saline-paired chamber $(p s<0.05)$. During a subsequent infusion-free CPP trial (i.e., trial 3), however, saline-treated rats but not propranolol-treated rats continued to express a CPP. Post hoc analysis confirmed that saline-treated rats spent significantly more time in the cocaine-paired chamber than in the salinepaired chamber during the infusion-free trial $(p<0.01)$, while propranolol-treated rats spent an equivalent amount of time in the cocaine- and saline-paired chambers $(p>0.05)$. The effect of propranolol was not due to nonspecific motor impairments as 


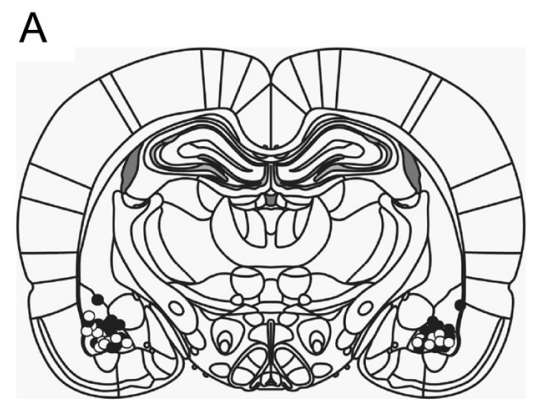

B

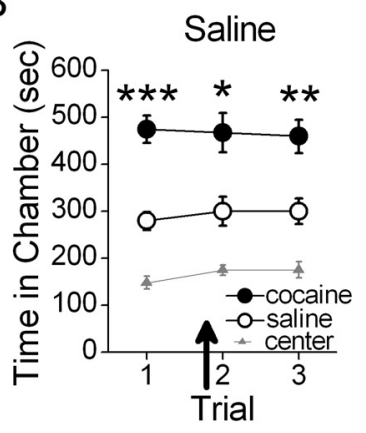

C

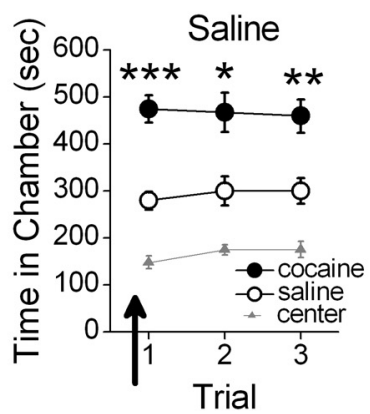

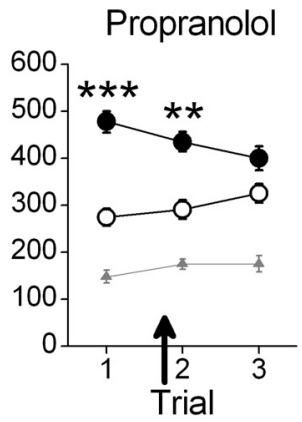

D

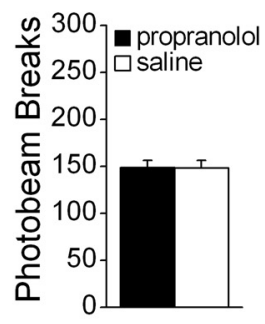

E

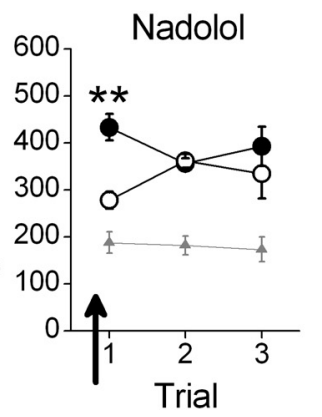

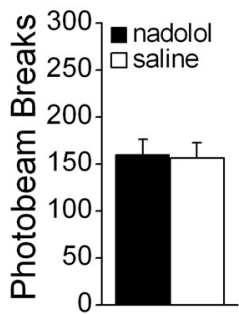

Figure 2. $\quad \beta$-AR blockade in BLA has no effect on CPP memory retrieval. $A$, Coronal drawings (bregma, $-2.76 \mathrm{~mm}$ ) showing injector tip placements for BLA infusions. BLA infusions (arrows) of $(B)$ propranolol before a second CPP trial or (C) nadolol before a first CPP trial, but not saline, had no effect on CPP expression during the infusion trial, but prevented CPP expression during subsequent infusion-free trials. BLA infusions of $(\boldsymbol{D})$ propranolol or $(\boldsymbol{E})$ nadolol had no effect on locomotor activity, as measured by photobeam breaks, when administered before a $C P P$ trial. ${ }^{* * *} p<0.001$, ${ }^{* *} p<0.01$, and ${ }^{*} p<0.05$. Error bars indicate SEM.

rats infused with propranolol $(n=9)$ or saline $(n=13)$ before a second CPP trial had equivalent photobeam breaks during that trial $\left(t_{(20)}=0.15, p>0.05\right.$; Fig. $\left.2 D\right)$. Together, a single BLA propranolol infusion had no effect on initial CPP memory retrieval, but prevented subsequent CPP expression indicative of reconsolidation disruption (Nader et al., 2000; Bernardi et al., 2009).

To confirm that the effects of propranolol on reconsolidation, but not retrieval, were specific to $\beta$-AR blockade, we infused nadolol into the BLA. Following conditioning, rats were subjected to daily CPP trials, with bilateral BLA microinfusions of saline $(n=13)$ or nadolol $(n=9)$ before the first trial. All rats expressed a CPP during the first CPP trial, but only saline-treated rats expressed a CPP during subsequent infusion-free trials (Fig. $2 C)$. ANOVA revealed a significant group by chamber effect $\left(F_{(2,40)}=3.48, p<0.05\right)$, but no group by chamber by trial interaction $\left(F_{(4,80)}=0.56, p>0.05\right)$. Post hoc analysis confirmed that both groups spent significantly more time in the previously cocaine-paired chamber during the first trial ( $p s<0.01$ ), indicating that both groups expressed a CPP. During subsequent microinfusion-free trials (i.e., trials 2-3), saline-infused rats continued to spend significantly more time in the cocaine-paired chamber than in the saline-paired chamber (post hoc $p<0.01$ ), while nadolol-treated rats spent an equivalent amount of time in the cocaine- and saline-paired chambers (post hoc $p>0.05$ ). Thus, only saline-treated rats expressed a CPP during the infusion-free trials. Moreover, the effects of nadolol were not due to nonspecific motor impairments as rats infused with saline $(n=$ 13 ) or nadolol $(n=9)$ before an initial CPP trial had comparable levels of photobeam breaks during that trial $\left(t_{(20)}=0.03, p>\right.$ 0.05; Fig. $2 E$ ). Thus, BLA microinfusions of $\beta$-AR antagonists had no effect on CPP memory retrieval, but likely disrupted CPP memory reconsolidation.

\section{PL-mPFC $\beta$-AR blockade has no effect on reconsolidation of a CPP memory}

No published investigations to date have examined the necessity of the PL-mPFC in drug-associated memory reconsolidation. Moreover, whether retrieval and reconsolidation of drugassociated memories are dependent on identical or distinct neurobiological mechanisms is unknown. Thus, we determined the necessity of $\beta$-AR activation within the PL-mPFC after retrieval for cocaine-associated CPP memory reconsolidation. Following conditioning, rats were subjected to daily CPP trials, with bilateral PL-mPFC microinfusions of saline $(n=9)$ or nadolol $(n=10)$ immediately after the first trial (Fig. $3 A$; PL-mPFC infusion sites). All rats expressed a CPP during the initial CPP trial and during subsequent drug-free trials (Fig. 3B). ANOVA revealed no significant group differences (group by chamber, $F_{(2,34)}=0.79, p>0.05$; group by chamber by trial, $F_{(4,68)}=$ $0.34, p>0.05)$, but indicated a significant effect of chamber overall $\left(F_{(2,34)}=73.12 ; p<0.001\right)$. Post hoc analysis confirmed that both saline- and nadolol-treated rats spent more time in the previously cocaine-paired chamber than in the saline-paired chamber during the first trial $(p s<0.001)$, and during the second and third trials overall ( $p s<0.05$ ). Thus, both groups expressed a CPP before and following PL-mPFC microinfusions, demonstrating that $\beta$-ARs within the PL$\mathrm{mPFC}$ are not involved in CPP memory reconsolidation.

\section{BLA $\boldsymbol{\beta}$-AR blockade prevents reconsolidation of a CPP memory}

We next directly investigated the necessity of BLA $\beta$-ARs for cocaine-associated memory reconsolidation. Following conditioning, rats were subjected to daily CPP trials, with bilateral BLA microinfusions of saline $(n=13)$ or nadolol $(n=10)$ immediately after the first trial (Fig. 3C; BLA infusion sites). All rats expressed a CPP 
during the first trial before microinfusions. During subsequent trials, however, salinetreated rats continued to express a CPP for the previously cocaine-paired chamber, while nadolol-treated rats did not (Fig. 3D). ANOVA revealed a significant group by chamber effect $\left(F_{(2,42)}=10.29, p<0.001\right)$, but no group by chamber by trial interaction $\left(F_{(4,84)}=1.86, p>0.05\right)$. Post hoc analysis confirmed that both groups spent significantly more time in the previously cocaine-paired than in the saline-paired chamber during the first trial ( $p s \leq 0.001$ ). However, while saline-treated rats continued to spend significantly more time in the previously cocaine-paired chamber than in the saline-paired chamber during subsequent infusion-free trials (i.e., trials 2-3), nadolol-treated rats did not (saline, post hoc $p<0.001$; nadolol, post hoc $p>0.05$ ). Thus, only saline-treated rats expressed a CPP following BLA microinfusions. Together, these data are consistent with the conclusion that BLA $\beta$-AR blockade prevents CPP memory reconsolidation.

\section{PL-mPFC and BLA $\beta$-AR blockade has no effect on CPP expression in the absence of retrieval}

The long-term effects of PL-mPFC or BLA $\beta$-AR blockade on CPP expression could be due to effects that are nonspecific to memory retrieval. To control for this, we first assessed the effects of PL-mPFC $\beta$-AR blockade in the absence of a CPP retrieval trial. Following conditioning, bilateral PL-mPFC microinfusions of saline $(n=12)$ or nadolol $(n=12)$ were administered in the absence of testing, followed by a CPP retrieval trial $24 \mathrm{~h}$ later. All rats expressed a CPP during this trial (Fig. 4). ANOVA revealed no group by chamber difference $\left(F_{(2,44)}=0.48, p>0.05\right)$, but indicated a significant effect of chamber overall $\left(F_{(2,44)}=74.78\right.$; $p<0.001)$. Post hoc analysis confirmed that both saline- and nadolol-treated rats spent more time in the previously cocainepaired chamber during the CPP trial $(p s<0.001)$. Thus, PLmPFC microinfusions of nadolol had no effect on CPP expression in the absence of memory retrieval.

We next determined the effects of BLA $\beta$-AR blockade in the absence of CPP memory retrieval. Following conditioning, bilateral BLA microinfusions of saline $(n=11)$ or nadolol $(n=12)$ were administered in the absence of testing, followed by a CPP retrieval trial $24 \mathrm{~h}$ later. All rats expressed a CPP during this trial (Fig. 4). ANOVA revealed no group by chamber differences $\left(F_{(2,42)}=0.73\right.$, $p>0.05)$, but indicated a significant effect of chamber overall $\left(F_{(2,42)}=83.62 ; p<0.001\right)$. Post hoc analysis confirmed that both saline- and nadolol-treated rats spent more time in the previously cocaine-paired chamber during the CPP trial ( $p s<0.001)$. Thus, BLA microinfusions of nadolol in the absence of a retrieval trial had no effect on subsequent CPP expression.

\section{PL-mPFC and BLA $\beta$-AR blockade is not aversive or appetitive}

We next examined whether PL-mPFC or BLA microinfusions of nadolol itself induced an affective state, which could have influenced $\mathrm{CPP}$ expression. Rats were conditioned to associate one chamber, but not another, with PL-mPFC microinfusions of nadolol $(n=12)$.
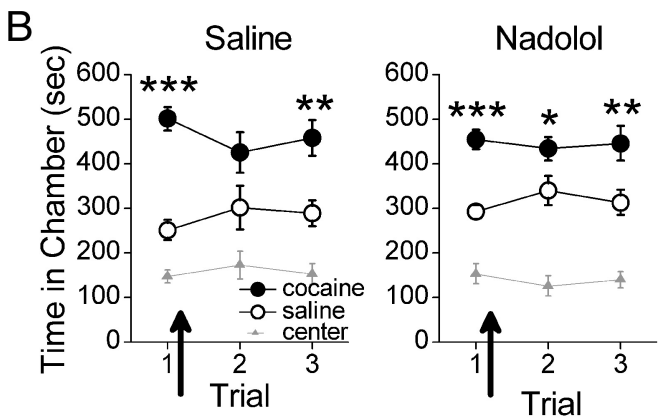

$\mathrm{D}$
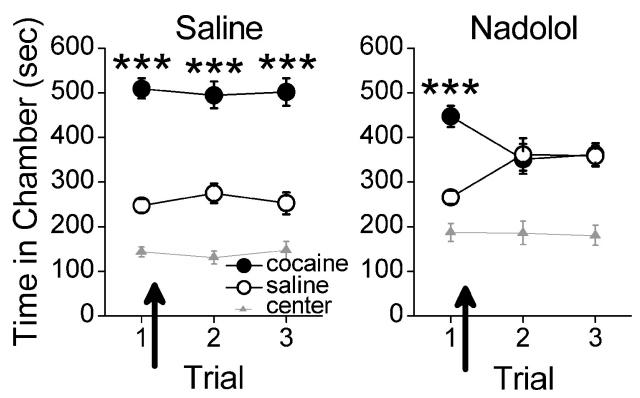

Figure 3. $\quad \beta$-AR blockade in BLA but not PL-mPFC disrupts reconsolidation of a CPP memory. $A$, Coronal drawings (bregma, infusions. D, BLA infusions (arrows) of nadolol immediately after a first CPP trial prevented subsequent CPP expression. ${ }^{* * *} p<$ $0.001,{ }^{* *} p<0.01$, and ${ }^{*} p<0.05$. Error bars indicate SEM.
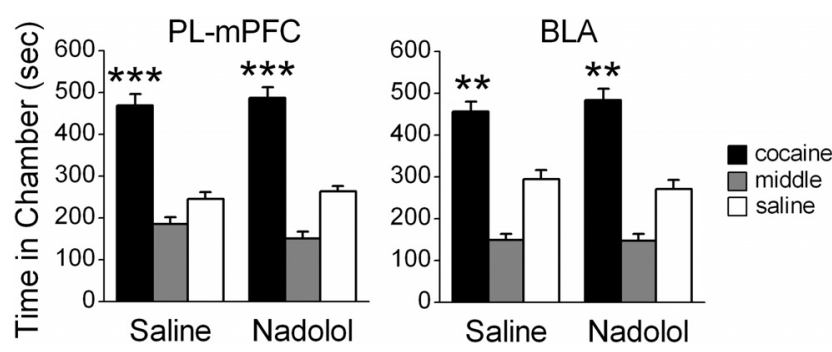

Figure 4. $\quad \beta$-AR blockade in PL-mPFC or BLA has no effect on CPP expression in the absence of retrieval. PL-mPFC (left) or BLA (right) infusions of nadolol $24 \mathrm{~h}$ before a CPP trial had no effect on CPP expression. ${ }^{* *} p<0.001,{ }^{* *} p<0.01$. Error bars indicate SEM.

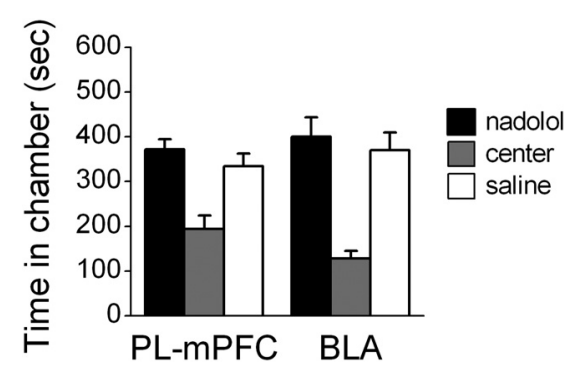

Figure 5. $\quad \beta$-AR blockade in PL-mPFC or BLA does not induce a CPP or aversion. Following conditioning with PL-mPFC or BLA microinfusions of nadolol or saline, rats spent an equivalent amount of time in the previously nadolol- and saline-paired chambers. Error bars indicate SEM.

PL-mPFC nadolol microinfusions had no effect on time spent in the conditioning chambers during a subsequent drug-free CPP trial (Fig. 5). ANOVA indicated an effect of chamber during this trial $\left(F_{(2,22)}=12.56, p<0.001\right)$, although post hoc analysis confirmed that an equivalent amount of time was spent within the previously cocaine- and saline-paired chambers $(p>0.05)$. Thus, PL-mPFC 
microinfusions of nadolol did not induce an affective state sufficient to induce a CPP or aversion. Next, we conditioned rats to associate one chamber, but not another, with BLA microinfusions of nadolol $(n=11)$. BLA nadolol microinfusions did not alter the amount of time spent within either conditioning chamber (Fig. 5). ANOVA indicated an effect of chamber during the CPP trial $\left(F_{(2,20)}=7.40\right.$, $p<0.01)$. However, post hoc analysis confirmed that an equivalent amount of time was spent within the previously nadolol- and salinepaired chamber $(p>0.05)$. Thus, neither PL-mPFC nor BLA microinfusions of nadolol induced a CPP or aversion.

\section{$\boldsymbol{\beta}$-AR blockade prevents NE-induced potentiation of}

PL-mPFC pyramidal neuron excitability

Intrinsic excitability of hippocampal, amygdalar, and cortical pyramidal neurons is potentiated by $\beta$-AR activation (Pedarzani and

\section{A}

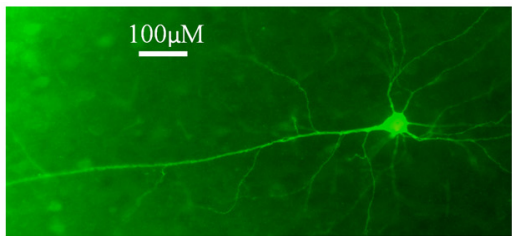

B

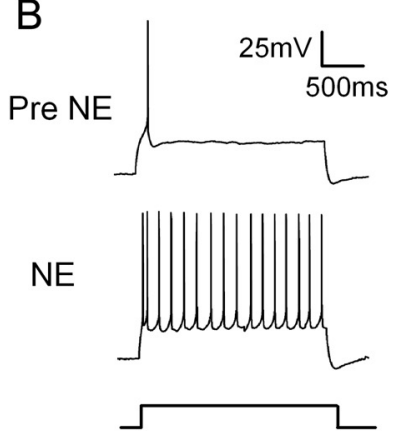

D

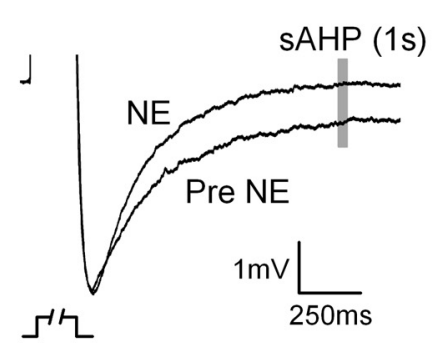

C

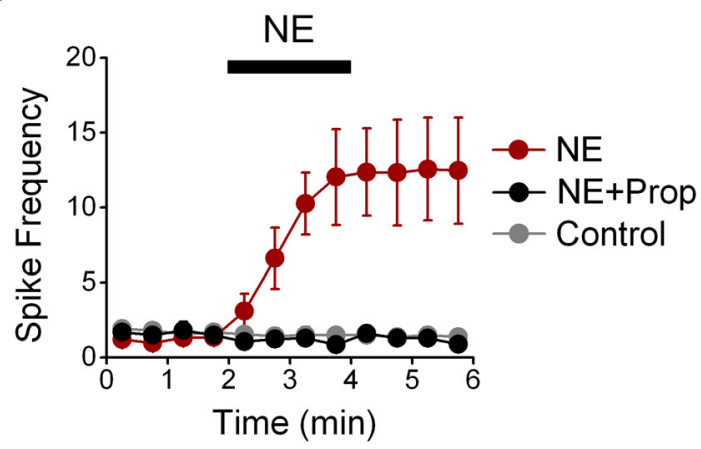

E

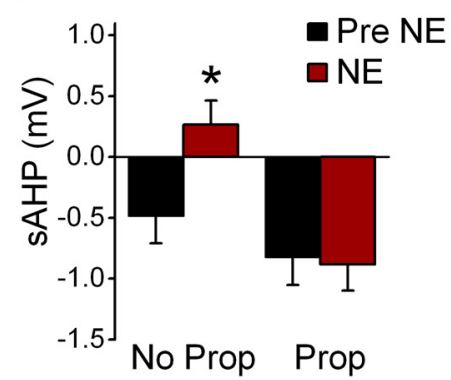

Figure 6. $\quad \beta$-AR blockade prevents NE-induced potentiation of PL-mPFC neuronal intrinsic excitability. $\boldsymbol{A}$, Photomicrograph of a biocytin-filled pyramidal neuron. $\boldsymbol{B}$, Individual traces of current-evoked APs from a PL-mPFC pyramidal neuron before and after NE application. $\boldsymbol{C}, \beta$-AR blockade prevents NE-induced increases in AP frequency. $\boldsymbol{D}$, Grouped traces revealing that NE transformed the sAHP to a SADP. $E, \beta$-AR blockade prevents NE-induced reversal of the SAHP. * $p<0.05$; Prop, propranolol. Error bars indicate SEM.
Storm, 1993; Brosh et al., 2006; Barth et al., 2007; Abraham et al., 2008; Mueller et al., 2008), offering a potential mechanism by which $\beta$-ARs mediate retrieval and reconsolidation. Whether $\beta$-AR blockade prevents NE-induced enhancement of intrinsic excitability in PL-mPFC pyramidal neurons, however, is unknown. To investigate this, we used patch-clamp electrophysiology to record APs evoked by brief current pulses in PL-mPFC pyramidal neurons (Fig. 6A). NE $(100 \mu \mathrm{M})$ increased the number of evoked APs (Fig. $6 B$ ). The effect of NE was blocked by bath application of propranolol (Fig. $6 C$ ), indicating that $\beta$-AR blockade prevents NE-induced potentiation of PL-mPFC neuron excitability. Comparing neurons treated with NE, NE + propranolol, and no drug controls, ANOVA revealed an effect of time $\left(F_{(11,176)}=12.86, p<0.001\right)$ and a treatment by time interaction $\left(F_{(22,176)}=14.79, p<0.001\right)$. Post hoc tests confirmed that NE significantly increased the number of APs compared with $\mathrm{NE}+$ propranolol-treated $(p<$ $0.001)$ and no drug control neurons $(p<$ 0.001). Moreover, NE caused membrane depolarization, decreased rheobase, and reduced AP latency (Table 2), also indicative of increased excitability. These changes were not present in NE + propranololtreated pyramidal neurons. Thus, NEinduced potentiation of intrinsic excitability was blocked by propranolol. Finally, although NE had no effect on fAHP in pyramidal neurons, NE transformed the sAHP to a slow afterdepolarization (Fig. 6D). As the sAHP limits AP frequency (Wu et al., 2004), reversal of the sAHP is a likely mechanism by which $\beta$-AR activation enhances the number of evoked APs. Consistent with this, propranolol prevented NE from reversing the sAHP (Fig. 6E).

\section{$\boldsymbol{\beta}$-AR blockade prevents NE-induced potentiation of PL-mPFC GABAergic neuron excitability}

Although the primary output neurons of the PL-mPFC are pyramidal neurons, these neurons function within a network of GABAergic interneurons. Thus, we also assessed the effect of NE and $\beta$-AR blockade on intrinsic excitability of PL-mPFC GABAergic neurons. GABAergic neurons were identified by morphology (lack of apical dendrite), electrophysiological characteristics (Table 1), and by streptavidin and $\mathrm{GAD}_{67}$ coimmunoreactivity (Fig. $7 \mathrm{~A}$ ). Similar to the effects of NE on pyramidal neurons, NE $(100 \mu \mathrm{M})$ increased the number of evoked APs (Fig. 7B). In contrast, the effect of NE was impaired by coapplication of pro-

Table 2. Effects of NE and propranolol on intrinsic excitability of PL-mPFC pyramidal neurons

\begin{tabular}{|c|c|c|c|c|c|c|c|c|}
\hline Drug & Time & $\mathrm{R}_{\mathrm{N}}(\mathrm{M} \Omega)$ & $V_{\mathrm{m}}(\mathrm{mV})$ & Rheo (pA) & $A P_{\text {thresh }}(\mathrm{mV})$ & $\mathrm{AP}_{\text {latency }}(\mathrm{ms})$ & fAHP $(m V)$ & $\mathrm{sAHP}(\mathrm{mV})$ \\
\hline \multirow[t]{2}{*}{$\mathrm{NE}$} & Pre & $121 \pm 24$ & $-70 \pm 3$ & $223 \pm 75$ & $-40 \pm 2$ & $118 \pm 18$ & $-7.3 \pm 0.7$ & $-0.5 \pm 0.2$ \\
\hline & Post & $124 \pm 30$ & $-65 \pm 3^{* *}$ & $173 \pm 74^{* *}$ & $-39 \pm 1$ & $53 \pm 8^{* *}$ & $-7.7 \pm 1.1$ & $0.3 \pm 0.2^{*}$ \\
\hline \multirow[t]{2}{*}{ Prop + NE } & Pre & $132 \pm 13$ & $-69 \pm 4$ & $93 \pm 11$ & $-41 \pm 5$ & $130 \pm 28$ & $-5.6 \pm 1.3$ & $-0.9 \pm 0.3$ \\
\hline & Post & $149 \pm 12$ & $-68 \pm 4$ & $88 \pm 18$ & $-41 \pm 4$ & $102 \pm 29$ & $-4.5 \pm 1.6$ & $-0.9 \pm 0.3$ \\
\hline
\end{tabular}


pranolol (Fig. 7C), indicating that $\beta$-AR blockade prevents NEinduced potentiation of PL-mPFC neuron excitability. Comparing GABAergic neurons treated with NE, NE + propranolol, and no drug controls, ANOVA revealed an effect of time $\left(\mathrm{F}_{11,341}\right)=15.06$, $p<0.001)$ and a treatment by time interaction $\left(F_{(22,341)}=8.19, p<\right.$ $0.001)$. Post hoc tests confirmed that NE significantly increased the number of APs compared with $\mathrm{NE}+$ propranolol-treated $(p<$ $0.001)$ and no drug control neurons $(p<0.01)$. Moreover, NE caused membrane depolarization, decreased rheobase, and reduced AP latency (Table 3), also indicative of increased excitability. However, propranolol treatment affected only rheobase without affecting membrane depolarization or reduced AP latency. Overall, NE-induced potentiation of GABAergic neuron excitability was blocked by propranolol. In contrast to pyramidal neurons, NE had no effect on the SAHP of GABAergic neurons, which is consistent with the idea that these neurons lack a sAHP (present findings; McCormick et al., 1985). However, NE reduced the amplitude of the fAHP in GABAergic neurons (Fig. 7D), an effect that was also blocked by propranolol (Fig. 7E). Thus, NE may potentiate the neuronal excitability of GABAergic neurons by reducing the fAHP.

\section{Discussion}

We demonstrate that cocaine-associated memory retrieval and reconsolidation are dependent on distinct neural mechanisms. PL-mPFC $\beta$-AR blockade induced a longterm deficit in cocaine-associated memory expression when administered before, but not after, a CPP retrieval trial. In contrast, while BLA $\beta$-AR blockade had no effect on initial CPP expression, BLA $\beta$-AR blockade before or immediately after a retrieval trial prevented CPP expression during subsequent trials. Thus, $\beta$-ARs within PL-mPFC are necessary for cocaine-associated memory retrieval but not reconsolidation, whereas $\beta$-ARs within BLA are necessary for cocaine-associated memory reconsolidation but not retrieval. Moreover, we found that $\beta$-AR blockade prevents potentiation of neuronal excitability by NE in both PLmPFC pyramidal and GABAergic neurons. Thus, $\beta$-AR-dependent modulation of neuronal excitability may be critical for cocaineassociated memory retrieval. These findings are the first to dissociate the neural mechanisms of drug-associated memory retrieval and reconsolidation, and offer a potential mechanism by which persistent retrieval deficits are induced.

Our findings are consistent with evidence demonstrating that PL-mPFC is critical for expression of associative memories. PL$\mathrm{mPFC}$ inactivation blocks expression of conditioned fear (Corcoran and Quirk, 2007) and cue-driven cocaine seeking (Hiranita et al., 2006), and PL-mPFC becomes active during drugassociated cue exposure (Miller and Marshall, 2004, 2005). Moreover, selective noradrenergic lesions in mPFC before conditioning prevent drug seeking (Ventura et al., 2003, 2007). Despite evidence that PL-mPFC drives behavioral expression of memories and drug seeking (for review, see Peters et al., 2009), our results are the first to reveal that disruption of PL-mPFC activity induces lasting disruptions in memory retrieval. We previously reported that systemically administered propranolol in-

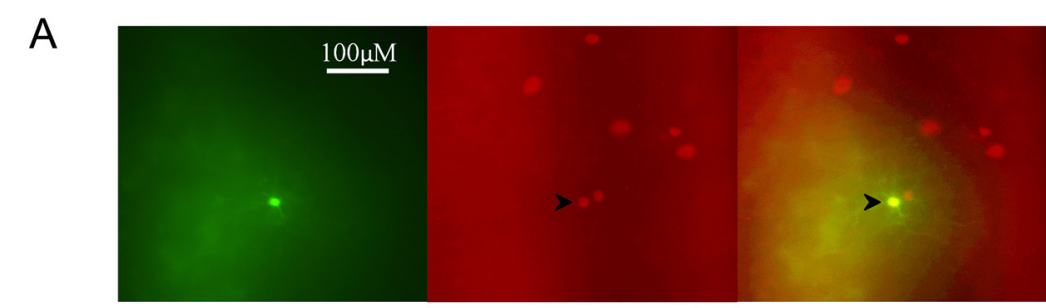

B

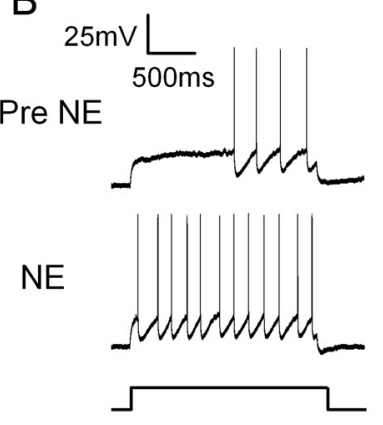

C

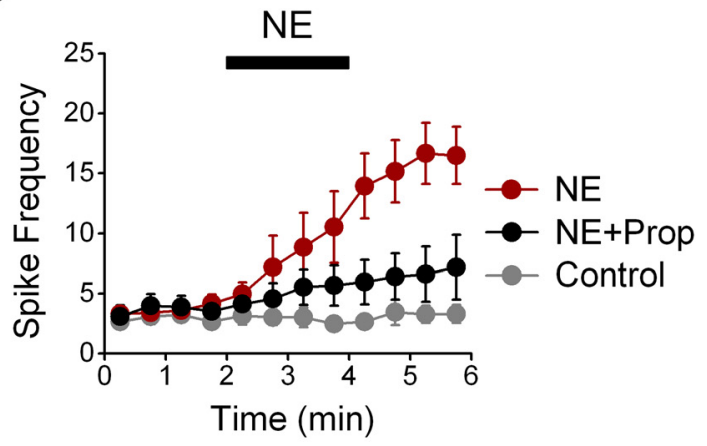

$E$

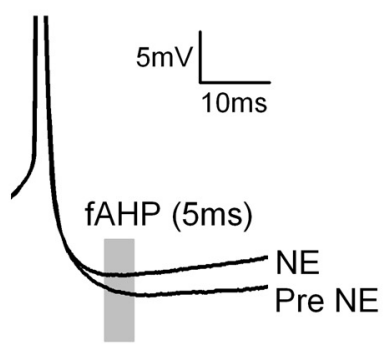

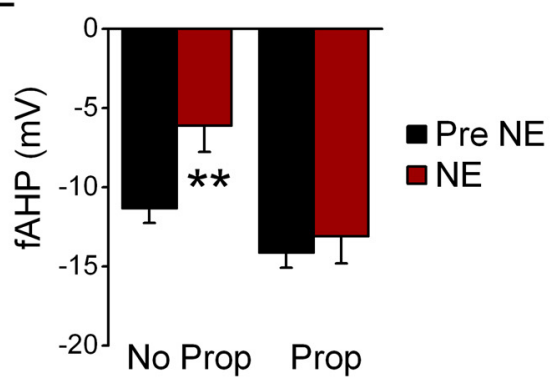

Figure 7. $\quad \beta$-AR blockade prevents NE-induced potentiation of PL-mPFC GABAergic neuronal intrinsic excitability. $\boldsymbol{A}$, Photomicrographs of a biocytin-filled PL-mPFC GABAergic neuron (left) and immunolabeled $\mathrm{GAD}_{67}$ neurons (middle; black arrowhead), which overlap (right). $\boldsymbol{B}$, Individual traces of current-evoked APs from a PL-mPFC GABAergic neuron before and after NE application. $\boldsymbol{C}, \beta$-AR blockade prevents NE-induced increases in AP frequency. $\boldsymbol{D}$, Grouped traces revealing that NE reduced the fAHP. $\boldsymbol{E}$, $\beta$-AR blockade prevents NE-induced reductions of the fAHP. ${ }^{* *} p<0.01$; Prop, propranolol. Error bars indicate SEM.

Table 3. Effects of NE and propranolol on intrinsic excitability of PL-mPFC GABAergic neurons

\begin{tabular}{|c|c|c|c|c|c|c|c|c|}
\hline Drug & Time & $\mathrm{R}_{\mathrm{N}}(\mathrm{M} \Omega)$ & $V_{\mathrm{m}}(\mathrm{mV})$ & Rheo (pA) & $\mathrm{AP}_{\text {thresh }}(\mathrm{mV})$ & $\mathrm{AP}_{\text {latency }}(\mathrm{ms})$ & fAHP (mV) & $\mathrm{sAHP}(\mathrm{mV})$ \\
\hline \multirow[t]{2}{*}{ NE } & Pre & $285 \pm 56$ & $-65 \pm 2$ & $74 \pm 15$ & $-42 \pm 2$ & $127 \pm 35$ & $-11 \pm 0.9$ & $0.0 \pm 0.1$ \\
\hline & Post & $231 \pm 39$ & $-60 \pm 2^{* *}$ & $31 \pm 9^{* *}$ & $-44 \pm 2$ & $32 \pm 10^{* *}$ & $-6.1 \pm 1.6^{* *}$ & $0.0 \pm 0.2$ \\
\hline \multirow[t]{2}{*}{ Prop + NE } & Pre & $333 \pm 52$ & $-69 \pm 3$ & $58 \pm 9$ & $-44 \pm 2$ & $148 \pm 44$ & $-14.1 \pm 1.0$ & $-0.2 \pm 0.2$ \\
\hline & Post & $365 \pm 53$ & $-69 \pm 3$ & $39 \pm 9^{*}$ & $-46 \pm 2$ & $83 \pm 23$ & $-13.1 \pm 1.7$ & $0.3 \pm 0.4$ \\
\hline
\end{tabular}


duces persistent deficits in cocaine-associated memory retrieval, an effect that is persistent and prevents subsequent cocaineinduced reinstatement (Otis and Mueller, 2011). Similarly, a recent study found a sustained reduction in retrieval of emotional words in humans following propranolol administration (Kroes et al., 2010). This converging evidence in rodents and humans supports our conclusion that $\beta$-AR blockade induces persistent deficits in retrieval, and that this effect is dependent on PL-mPFC $\beta$-ARs.

Exposure to previously cocaine- or shock-paired conditioned stimuli activates markers associated with protein synthesis within PL-mPFC, including immediate early genes (e.g., Arc and c-fos), CaMKII, and CREB (Ciccocioppo et al., 2001; Miller and Marshall, 2004; Mamiya et al., 2009). These alterations correspond with those known to be required for memory reconsolidation in other brain regions (Milton et al., 2008b; Mamiya et al., 2009; Maddox and Schafe, 2011; Tronson et al., 2012), indicating that PL-mPFC protein synthesis may be involved in memory reconsolidation. However, PL-mPFC protein synthesis inhibition has no effect on reconsolidation of recent or remote fear memories (Blum et al., 2006). Considering that $\beta$-AR activation induces protein synthesis via PKA signaling cascades (Seeds and Gilman, 1971; Pedarzani and Storm, 1993; Mayr and Montminy, 2001; Mueller and Cahill, 2010), our data indicate that PL-mPFC $\beta$-AR-dependent protein synthesis is not required for memory reconsolidation. The specific $\beta$-AR-dependent modifications that mediate maintenance of drug-associated memory retrieval, however, are unknown.

We found that BLA $\beta$-AR activity is not required for drugassociated memory retrieval, although evidence suggests that BLA is necessary for expression and reconsolidation of associative memories. The BLA mediates cue-induced drug seeking (Brown and Fibiger, 1993; Grimm and See, 2000), and becomes active upon exposure to drug-associated cues in both rats (Miller and Marshall, 2004) and humans (Grant et al., 1996). In the BLA, however, protein kinase A (PKA; which is downstream of $\beta$-ARs) (Pedarzani and Storm, 1993; Raman et al., 1996) is not required for CPP expression (Lai et al., 2008). Thus, BLA $\beta$-adrenergic signaling is not required for CPP memory retrieval. In contrast, BLA $\beta$-AR activation has been implicated in memory reconsolidation. For example, inhibition of the transcription factor Zif268 within the amygdala reduces cue-induced cocaine seeking and relapse, cue-induced fear, and eliminates the conditioned reinforcing properties of cocaine-related cues (Lee et al., 2005, 2006). Importantly, BLA infusions of propranolol or a PKA inhibitor following exposure to a retrieval cue prevent subsequent expression of both fear- and cocaine-associated memories (Debiec and Ledoux, 2004; Tronson et al., 2006; Bernardi et al., 2009; Sanchez et al., 2010; Wu et al., 2012). These findings support our conclusion that BLA $\beta$-AR signaling is necessary for drug-associated memory reconsolidation, but not retrieval. Whether retrieval is dependent on BLA activity that is independent of $\beta$-ARs, however, remains unknown.

Our results reveal that $\beta$-AR blockade prevents NE-induced potentiation of intrinsic excitability in PL-mPFC pyramidal neurons by preventing NE-induced sAHP reversal. These findings parallel those from hippocampal and infralimbic pyramidal neurons, which demonstrate that inhibition of $\beta$-ARs or downstream signaling cascades prevents NE-induced reductions in spike-frequency adaptation (Madison and Nicoll, 1982; Pedarzani and Storm, 1993), and NE-induced reductions in sAHP amplitude and duration (Madison and Nicoll, 1986a,b; Pedarzani and Storm, 1993; Mueller et al., 2008). Similarly, we found that propranolol prevents NE-induced potentiation of GABAergic neuron excitability. These effects were likely due to reduction in the amplitude of fAHP, but not SAHP. This is consistent with our results demonstrating that PL-mPFC GABAergic neurons lack a sAHP, but have enhanced fAHP (McCormick et al., 1985; Karayannis et al., 2007). Thus, stimulation of $\beta$-adrenergic signaling by NE enhances excitability of PL-mPFC pyramidal and GABAergic neurons by reducing the sAHP and fAHP, respectively. These data suggest that cocaine-associated cues evoke PL-mPFC neuronal excitation, and that this underlies cocaine-associated memory retrieval by selectively enhancing evoked firing while simultaneously reducing spontaneous firing.

Our findings that NE-enhanced intrinsic excitability of PLmPFC neurons is dependent on $\beta$-ARs complement previous work showing that $\beta$-ARs regulate $\mathrm{mPFC}$ synaptic activity. $\beta$-AR activation enhances excitatory currents within mPFC, effects which are inhibited by propranolol, PKA inhibition, or MAPK inhibition (Huang and Hsu, 2006; Ji et al., 2008). These potentiated currents result from enhancement of both postsynaptic NMDA receptor activity and presynaptic non-NMDA receptor activity (Ji et al., 2008). $\beta$-AR activation also restores spike-timing-dependent potentiation of synapses within $\mathrm{mPFC}$, likely through inhibition of the sAHP (Zaitsev and Anwyl, 2012). Thus, $\beta$-AR activation within $\mathrm{mPFC}$ enhances basal excitatory synaptic transmission and increases the probability of long-term synaptic plasticity. Together, the shortand long-term effects of $\beta$-AR blockade on CPP memory retrieval are likely mediated by inhibition of NE-enhanced intrinsic excitability and synaptic potentiation.

Although retrieval and reconsolidation are dependent on distinct neural mechanisms, retrieval is necessary for successful reconsolidation. The BLA becomes active during drug-associated cue presentation (Ciccocioppo et al., 2001; Miller and Marshall, 2005; Childress et al., 2008; Goudriaan et al., 2010), and this activity is necessary for both cue-induced drug seeking (Fuchs et al., 2005; McDonald et al., 2010) and the initiation of memory reconsolidation (Kim et al., 2010; McDonald et al., 2010). In parallel, cue-induced $\beta$-AR activation within PL-mPFC induces memory retrieval (as described above) and could provide feedback to the BLA, restabilizing the memory via induction of protein synthesis and synaptic plasticity (Nader et al., 2000; Doyère et al., 2007). This interpretation is consistent with data revealing that the hippocampus and amygdala interact to mediate memory reconsolidation in both cocaine-self administration and contextual fear paradigms (Debiec et al., 2002; Wells et al., 2011). However, this interpretation is inconsistent with data showing that BLA-projecting PL-mPFC neurons are not active following CPP expression (Miller and Marshall, 2005). Rather, PL-mPFCprojecting BLA neurons become active (Miller and Marshall, 2005), indicating that PL-mPFC activity is downstream, not upstream, of BLA activity following drug-associated cue exposure. Despite this, it is possible that $\beta$-AR-dependent PL-mPFC activation stabilizes memory reconsolidation through a multisynaptic connection.

The possibility that PL-mPFC and BLA $\beta$-AR blockade facilitated extinction, rather than impaired memory retrieval and reconsolidation, cannot be completely ruled out. This is unlikely, however, given that NE enhances, rather than impedes, memory formation and extinction through $\beta$-AR activation (McGaugh, 2000; Mueller and Cahill, 2010). Furthermore, research has demonstrated that $\beta$-AR blockade impairs extinction (for review, see Mueller and Cahill, 2010) across multiple memory paradigms 
(Merlo and Izquierdo, 1967; LaLumiere and Kalivas, 2008; Mueller et al., 2008; Do-Monte et al., 2010).

Drug-associated cues evoke cravings and drug seeking in addicts, and disruption of these associations would therefore limit relapse susceptibility. Rehabilitation programs using exposure therapy, in which recovering addicts are presented with drugassociated cues in the absence of drug reinforcement, have had limited success in the absence of pharmacological adjuncts (O'Brien et al., 1990; Conklin and Tiffany, 2002). However, there are currently no FDA-approved pharmacological adjuvants to exposure therapy for the treatment of addiction. Our findings suggest that targeting drug-associated memories, through $\beta$-AR blockade, would limit relapse susceptibility by provoking sustained reductions in drug-associated memory retrieval or reconsolidation. In support of this, clinical studies have demonstrated that treating human addicts with the NE inhibitor disulfiram (Carroll et al., 1998, 2004; George et al., 2000; Petrakis et al., 2000) or $\beta$-AR antagonist propranolol (Kampman et al., 2001, 2006) improves treatment retention in the absence of exposure therapy. These findings could be due to disruption of drug-associated memory retrieval or reconsolidation, preventing cue-induced craving and relapse. Together, coupling exposure therapy with $\beta$-AR antagonists may cause a powerful disruption in drugassociated memories, providing a novel method of preventing cue-induced relapse long after treatment.

\section{References}

Abraham PA, Xing G, Zhang L, Yu EZ, Post R, Gamble EH, Li H (2008) beta1- and beta2-adrenoceptor induced synaptic facilitation in rat basolateral amygdala. Brain Res 1209:65-73. CrossRef Medline

Alexander BS, Wood MD (1987) Stereoselective blockade of central [3H]5hydroxytryptamine binding to multiple sites (5-HT1A, 5-HT1B and 5-HT1C) by mianserin and propranolol. J Pharm Pharmacol 39:664-666. Medline

Barth AM, Vizi ES, Lendvai B (2007) Noradrenergic enhancement of Ca2+ responses of basal dendrites in layer 5 pyramidal neurons of the prefrontal cortex. Neurochem Int 51:323-327. CrossRef Medline

Bernardi RE, Ryabinin AE, Berger SP, Lattal KM (2009) Post-retrieval disruption of a cocaine conditioned place preference by systemic and intrabasolateral amygdala beta2- and alpha1-adrenergic antagonists. Learn Mem 16:777-789. CrossRef Medline

Blum S, Runyan JD, Dash PK (2006) Inhibition of prefrontal protein synthesis following recall does not disrupt memory for trace fear conditioning. BMC Neurosci 7:67. CrossRef Medline

Brosh I, Rosenblum K, Barkai E (2006) Learning-induced reversal of the effect of noradrenalin on the postburst AHP. J Neurophysiol 96:1728-1733. CrossRef Medline

Brown EE, Fibiger HC (1993) Differential effects of excitotoxic lesions of the amygdala on cocaine-induced conditioned locomotion and conditioned place preference. Psychopharmacology 113:123-130. CrossRef Medline

Carroll KM, Nich C, Ball SA, McCance E, Rounsavile BJ (1998) Treatment of cocaine and alcohol dependence with psychotherapy and disulfiram. Addiction 93:713-727. CrossRef Medline

Carroll KM, Fenton LR, Ball SA, Nich C, Frankforter TL, Shi J, Rounsaville BJ (2004) Efficacy of disulfiram and cognitive behavior therapy in cocainedependent outpatients: a randomized placebo-controlled trial. Arch Gen Psychiatry 61:264-272. CrossRef Medline

Childress AR, McLellan AT, O’Brien CP (1986) Role of conditioning factors in the development of drug dependence. Psychiatr Clin North Am 9:413-425. Medline

Childress AR, Ehrman RN, Wang Z, Li Y, Sciortino N, Hakun J, Jens W, Suh J, Listerud J, Marquez K, Franklin T, Langleben D, Detre J, O’Brien CP (2008) Prelude to passion: limbic activation by "unseen" drug and sexual cues. PLoS One 3:e1506. CrossRef Medline

Ciccocioppo R, Sanna PP, Weiss F (2001) Cocaine-predictive stimulus induces drug-seeking behavior and neural activation in limbic brain regions after multiple months of abstinence: reversal by $\mathrm{D}(1)$ antagonists. Proc Natl Acad Sci U S A 98:1976-1981. CrossRef Medline

Conklin CA, Tiffany ST (2002) Applying extinction research and theory to cue-exposure addiction treatments. Addiction 97:155-167. CrossRef Medline

Corcoran KA, Quirk GJ (2007) Activity in prelimbic cortex is necessary for the expression of learned, but not innate, fears. J Neurosci 27:840-844. CrossRef Medline

Debiec J, Ledoux JE (2004) Disruption of reconsolidation but not consolidation of auditory fear conditioning by noradrenergic blockade in the amygdala. Neuroscience 129:267-272. CrossRef Medline

Debiec J, LeDoux JE, Nader K (2002) Cellular and systems reconsolidation in the hippocampus. Neuron 36:527-538. CrossRef Medline

Do-Monte FH, Kincheski GC, Pavesi E, Sordi R, Assreuy J, Carobrez AP (2010) Role of beta-adrenergic receptors in the ventromedial prefrontal cortex during contextual fear extinction in rats. Neurobiol Learn Mem 94:318-328. CrossRef Medline

Doyère V, Debiec J, Monfils MH, Schafe GE, LeDoux JE (2007) Synapsespecific reconsolidation of distinct fear memories in the lateral amygdala. Nat Neurosci 10:414-416. Medline

Fricks-Gleason AN, Marshall JF (2008) Post-retrieval beta-adrenergic receptor blockade: effects on extinction and reconsolidation of cocaine-cue memories. Learn Mem 15:643-648. CrossRef Medline

Fuchs RA, Evans KA, Ledford CC, Parker MP, Case JM, Mehta RH, See RE (2005) The role of the dorsomedial prefrontal cortex, basolateral amygdala, and dorsal hippocampus in contextual reinstatement of cocaine seeking in rats. Neuropsychopharmacology 30:296-309. CrossRef Medline

George TP, Chawarski MC, Pakes J, Carroll KM, Kosten TR, Schottenfeld RS (2000) Disulfiram versus placebo for cocaine dependence in buprenorphine-maintained subjects: a preliminary trial. Biol Psychiatry 47:1080-1086. CrossRef Medline

Goodman LS, Gilman A, Hardman JG, Limbird LE, Gilman AG (2001) Goodman and Gilman's the pharmacological basis of therapeutics, Ed 10. New York: McGraw-Hill.

Goudriaan AE, de Ruiter MB, van den Brink W, Oosterlaan J, Veltman DJ (2010) Brain activation patterns associated with cue reactivity and craving in abstinent problem gamblers, heavy smokers and healthy controls: an fMRI study. Addict Biol 15:491-503. CrossRef Medline

Grant S, London ED, Newlin DB, Villemagne VL, Liu X, Contoreggi C, Phillips RL, Kimes AS, Margolin A (1996) Activation of memory circuits during cue-elicited cocaine craving. Proc Natl Acad Sci U S A 93:12040-12045. CrossRef Medline

Grimm JW, See RE (2000) Dissociation of primary and secondary rewardrelevant limbic nuclei in an animal model of relapse. Neuropsychopharmacology 22:473-479. CrossRef Medline

Han J, Li Y, Wang D, Wei C, Yang X, Sui N (2010) Effect of 5-aza-2deoxycytidine microinjecting into hippocampus and prelimbic cortex on acquisition and retrieval of cocaine-induced place preference in C57BL/6 mice. Eur J Pharmacol 642:93-98. CrossRef Medline

Heather N, Stallard A, Tebbutt J (1991) Importance of substance cues in relapse among heroin users: comparison of two methods of investigation. Addict Behav 16:41-49. CrossRef Medline

Hiranita T, Nawata Y, Sakimura K, Anggadiredja K, Yamamoto T (2006) Suppression of methamphetamine-seeking behavior by nicotinic agonists. Proc Natl Acad Sci U S A 103:8523-8527. CrossRef Medline

Huang CC, Hsu KS (2006) Presynaptic mechanism underlying cAMPinduced synaptic potentiation in medial prefrontal cortex pyramidal neurons. Mol Pharmacol 69:846-856. Medline

Ji XH, Cao XH, Zhang CL, Feng ZJ, Zhang XH, Ma L, Li BM (2008) Pre- and postsynaptic beta-adrenergic activation enhances excitatory synaptic transmission in layer V/VI pyramidal neurons of the medial prefrontal cortex of rats. Cereb Cortex 18:1506-1520. Medline

Kaczorowski CC, Davis SJ, Moyer JR Jr (2012) Aging redistributes medial prefrontal neuronal excitability and impedes extinction of trace fear conditioning. Neurobiol Aging 33:1744-1757. CrossRef Medline

Kampman KM, Volpicelli JR, Mulvaney F, Alterman AI, Cornish J, Gariti P, Cnaan A, Poole S, Muller E, Acosta T, Luce D, O’Brien C (2001) Effectiveness of propranolol for cocaine dependence treatment may depend on cocaine withdrawal symptom severity. Drug Alcohol Depend 63:69-78. CrossRef Medline

Kampman KM, Dackis C, Lynch KG, Pettinati H, Tirado C, Gariti P, Sparkman T, Atzram M, O’Brien CP (2006) A double-blind, placebocontrolled trial of amantadine, propranolol, and their combination for 
the treatment of cocaine dependence in patients with severe cocaine withdrawal symptoms. Drug Alcohol Depend 85:129-137. CrossRef Medline

Karayannis T, Huerta-Ocampo I, Capogna M (2007) GABAergic and pyramidal neurons of deep cortical layers directly receive and differently integrate callosal input. Cereb Cortex 17:1213-1226. Medline

Kilts CD, Schweitzer JB, Quinn CK, Gross RE, Faber TL, Muhammad F, Ely TD, Hoffman JM, Drexler KP (2001) Neural activity related to drug craving in cocaine addiction. Arch Gen Psychiatry 58:334-341. CrossRef Medline

Kim J, Song B, Hong I, Kim J, Lee J, Park S, Eom JY, Lee CJ, Lee S, Choi S (2010) Reactivation of fear memory renders consolidated amygdala synapses labile. J Neurosci 30:9631-9640. Medline

Kroes MC, Strange BA, Dolan RJ (2010) Beta-adrenergic blockade during memory retrieval in humans evokes a sustained reduction of declarative emotional memory enhancement. J Neurosci 30:3959-3963. CrossRef Medline

Lai YT, Fan HY, Cherng CG, Chiang CY, Kao GS, Yu L (2008) Activation of amygdaloid PKC pathway is necessary for conditioned cues-provoked cocaine memory performance. Neurobiol Learn Mem 90:164-170. CrossRef Medline

LaLumiere RT, Kalivas PW (2008) Glutamate release in the nucleus accumbens core is necessary for heroin seeking. J Neurosci 28:3170-3177. CrossRef Medline

Lee JL, Di Ciano P, Thomas KL, Everitt BJ (2005) Disrupting reconsolidation of drug memories reduces cocaine-seeking behavior. Neuron 47: 795-801. CrossRef Medline

Lee JL, Milton AL, Everitt BJ (2006) Cue-induced cocaine seeking and relapse are reduced by disruption of drug memory reconsolidation. J Neurosci 26:5881-5887. CrossRef Medline

Loughlin SE, Foote SL, Fallon JH (1982) Locus coeruleus projections to cortex: topography, morphology and collateralization. Brain Res Bull 9:287-294. CrossRef Medline

Maddox SA, Schafe GE (2011) The activity-regulated cytoskeletalassociated protein (Arc/Arg3.1) is required for reconsolidation of a Pavlovian fear memory. J Neurosci 31:7073-7082. CrossRef Medline

Madison DV, Nicoll RA (1982) Noradrenaline blocks accommodation of pyramidal cell discharge in the hippocampus. Nature 299:636-638. CrossRef Medline

Madison DV, Nicoll RA (1986a) Actions of noradrenaline recorded intracellularly in rat hippocampal CA1 pyramidal neurones, in vitro. J Physiol 372:221-244. Medline

Madison DV, Nicoll RA (1986b) Cyclic adenosine 3',5'-monophosphate mediates beta-receptor actions of noradrenaline in rat hippocampal pyramidal cells. J Physiol 372:245-259. Medline

Mamiya N, Fukushima H, Suzuki A, Matsuyama Z, Homma S, Frankland PW, Kida S (2009) Brain region-specific gene expression activation required for reconsolidation and extinction of contextual fear memory. J Neurosci 29:402-413. CrossRef Medline

Mayr B, Montminy M (2001) Transcriptional regulation by the phosphorylation-dependent factor CREB. Nat Rev Mol Cell Biol 2:599-609. CrossRef Medline

McCormick DA, Connors BW, Lighthall JW, Prince DA (1985) Comparative electrophysiology of pyramidal and sparsely spiny stellate neurons of the neocortex. J Neurophysiol 54:782-806. Medline

McDonald RJ, Yim TT, Lehmann H, Sparks FT, Zelinski EL, Sutherland RJ, Hong NS (2010) Expression of a conditioned place preference or spatial navigation task following muscimol-induced inactivations of the amygdala or dorsal hippocampus: a double dissociation in the retrograde direction. Brain Res Bull 83:29-37. CrossRef Medline

McGaugh JL (2000) Memory-a century of consolidation. Science 287: 248-251. CrossRef Medline

Merlo AB, Izquierdo I (1967) The effect of catecholamines on learning in rats. Med Pharmacol Exp Int J Exp Med 16:343-349. Medline

Miller CA, Marshall JF (2004) Altered prelimbic cortex output during cueelicited drug seeking. J Neurosci 24:6889-6897. CrossRef Medline

Miller CA, Marshall JF (2005) Altered Fos expression in neural pathways underlying cue-elicited drug seeking in the rat. Eur J Neurosci 21: 1385-1393. CrossRef Medline

Milton AL, Lee JL, Everitt BJ (2008a) Reconsolidation of appetitive memories for both natural and drug reinforcement is dependent on $\{$ beta\}adrenergic receptors. Learn Mem 15:88-92. CrossRef Medline

Milton AL, Lee JL, Butler VJ, Gardner R, Everitt BJ (2008b) Intra-amygdala and systemic antagonism of NMDA receptors prevents the reconsolidation of drug-associated memory and impairs subsequently both novel and previously acquired drug-seeking behaviors. J Neurosci 28:8230-8237. CrossRef Medline

Mueller D, Cahill SP (2010) Noradrenergic modulation of extinction learning and exposure therapy. Behav Brain Res 208:1-11. CrossRef Medline

Mueller D, Stewart J (2000) Cocaine-induced conditioned place preference: reinstatement by priming injections of cocaine after extinction. Behav Brain Res 115:39-47. CrossRef Medline

Mueller D, Porter JT, Quirk GJ (2008) Noradrenergic signaling in infralimbic cortex increases cell excitability and strengthens memory for fear extinction. J Neurosci 28:369-375. CrossRef Medline

Murchison CF, Zhang XY, Zhang WP, Ouyang M, Lee A, Thomas SA (2004) A distinct role for norepinephrine in memory retrieval. Cell 117:131-143. CrossRef Medline

Nader K, Schafe GE, Le Doux JE (2000) Fear memories require protein synthesis in the amygdala for reconsolidation after retrieval. Nature 406: 722-726. CrossRef Medline

O'Brien CP, Childress AR, McLellan T, Ehrman R (1990) Integrating systemic cue exposure with standard treatment in recovering drug dependent patients. Addict Behav 15:355-365. CrossRef Medline

Otis JM, Mueller D (2011) Inhibition of beta-adrenergic receptors induces a persistent deficit in retrieval of a cocaine-associated memory providing protection against reinstatement. Neuropsychopharmacology 36:1912-1920. CrossRef Medline

Pedarzani P, Storm JF (1993) PKA mediates the effects of monoamine transmitters on the $\mathrm{K}+$ current underlying the slow spike frequency adaptation in hippocampal neurons. Neuron 11:1023-1035. CrossRef Medline

Peters J, Kalivas PW, Quirk GJ (2009) Extinction circuits for fear and addiction overlap in prefrontal cortex. Learn Mem 16:279-288. CrossRef Medline

Petrakis IL, Carroll KM, Nich C, Gordon LT, McCance-Katz EF, Frankforter T, Rounsaville BJ (2000) Disulfiram treatment for cocaine dependence in methadone-maintained opioid addicts. Addiction 95:219-228. CrossRef Medline

Raman IM, Tong G, Jahr CE (1996) Beta-adrenergic regulation of synaptic NMDA receptors by cAMP-dependent protein kinase. Neuron 16:415-421. CrossRef Medline

Sanchez H, Quinn JJ, Torregrossa MM, Taylor JR (2010) Reconsolidation of a cocaine-associated stimulus requires amygdalar protein kinase A. J Neurosci 30:4401-4407. CrossRef Medline

Santini E, Quirk GJ, Porter JT (2008) Fear conditioning and extinction differentially modify the intrinsic excitability of infralimbic neurons. J Neurosci 28:4028-4036. CrossRef Medline

Seeds NW, Gilman AG (1971) Norepinephrine stimulated increase of cyclic AMP levels in developing mouse brain cell cultures. Science 174:292. CrossRef Medline

Sozzani S, Agwu DE, McCall CE, O’Flaherty JT, Schmitt JD, Kent JD, McPhail LC (1992) Propranolol, a phosphatidate phosphohydrolase inhibitor, also inhibits protein kinase C. J Biol Chem 267:20481-20488. Medline

Storm JF (1987) Action potential repolarization and a fast after-hyperpolarization in rat hippocampal pyramidal cells. J Physiol 385:733-759. Medline

Tronson NC, Wiseman SL, Olausson P, Taylor JR (2006) Bidirectional behavioral plasticity of memory reconsolidation depends on amygdalar protein kinase A. Nat Neurosci 9:167-169. CrossRef Medline

Tronson NC, Wiseman SL, Neve RL, Nestler EJ, Olausson P, Taylor JR (2012) Distinctive roles for amygdalar CREB in reconsolidation and extinction of fear memory. Learn Mem 19:178-181. CrossRef Medline

Ventura R, Cabib S, Alcaro A, Orsini C, Puglisi-Allegra S (2003) Norepinephrine in the prefrontal cortex is critical for amphetamine-induced reward and mesoaccumbens dopamine release. J Neurosci 23:1879-1885. Medline

Ventura R, Morrone C, Puglisi-Allegra S (2007) Prefrontal/accumbal catecholamine system determines motivational salience attribution to both rewardand aversion-related stimuli. Proc Natl Acad Sci U S A 104:5181-5186. CrossRef Medline

Wells AM, Lasseter HC, Xie X, Cowhey KE, Reittinger AM, Fuchs RA (2011) Interaction between the basolateral amygdala and dorsal hippocampus is critical for cocaine memory reconsolidation and subsequent drug contextinduced cocaine-seeking behavior in rats. Learn Mem 18:693-702. Medline

Wu WW, Chan CS, Disterhoft JF (2004) Slow afterhyperpolarization 
governs the development of NMDA receptor-dependent afterdepolarization in CA1 pyramidal neurons during synaptic stimulation. J Neurophysiol 92:2346-2356. CrossRef Medline

Wu Y, Li Y, Yang X, Sui N (2012) Differential effect of beta-adrenergic receptor antagonism in basolateral amygdala on reconsolidation of aversive and appetitive memories associated with morphine in rats.
Addict Biol. Advance online publication. Retrieved June 25, 2012. doi:10.1111/j.1369-1600.2012.00443.x. CrossRef

Zaitsev AV, Anwyl R (2012) Inhibition of the slow afterhyperpolarization restores the classical spike timing-dependent plasticity rule obeyed in layer 2/3 pyramidal cells of the prefrontal cortex. J Neurophysiol 107:205215. CrossRef Medline 